\title{
МАРКЕТИНГОВЫЕ ИССЛЕДОВАНИЯ ИНСТИТУЦИОНАЛЬНЫХ МЕХАНИЗМОВ ВЗАИМОДЕЙСТВИЯ ОТРАСЛЕВОГО РЫНКА И СПОРТИВНОГО МЕНЕДЖМЕНТА
}

\author{
(C) 2020 Попова Елена Александровна \\ доктор экономических наук, доцент \\ Южно-Уральский государственный университет \\ (Национальный Исследовательский Университет), Россия, Челябинск \\ E-mail:73519045153@yandex.ru \\ (c) 2020 Демина Надежда Константиновна \\ кандидат экономических наук \\ Южно-Уральский государственный университет \\ (Национальный Исследовательский Университет), Россия, Челябинск \\ E-mail:deminank@susu.ru
}

Показана взаимосвязь (с позиций маркетинга) отраслевого рынка и спортивного менеджмента. Обоснован комплексный подход к маркетинговым исследованиям в сфере физкультурноспортивной деятельности. Особое внимание уделено структуризации институциональных форм взаимодействия отраслевого рынка и спортивного менеджмента.

Ключевые слова: маркетинг, комплексность, отраслевой рынок, спортивный менеджмент, институцииональный механизм.

Введение. Современное развитие экономической формации выходит на объективизацию рыночных отношений в различных сферах общественного взаимодействия, пусковым механизмом мотивации субъектов к совершению рыночных сделок является (по А.Смиту) стремление человека к максимизации удовлетворения своих потребностей в условиях ограниченных ресурсов. Развитие социально-экономической системы происходит стремительно, как производственные отрасли, так и сферы услуг, рыночные механизмы подвергаются трансформации в условиях изменений внешней среды, в частности, введение карантинных мероприятий привело к актуализации вопроса выбора конкурентной стратегии в отрасли физкультурноспортивных услуг.

Рынок как институциональный механизм согласно М.Веберу предусматривает добровольность участия в сделке, обусловленную рациональным, свободным выбором продавцов и покупателей благ. С развитием общественных систем взаимодействия рыночные механизмы проникают во многие сферы социальной жизни, в том числе в отрасль физкультурно-оздоровительной деятельности, роль государства в регулировании данных отраслей постепенно снижается и пере- ходит на стадию саморегулирования на уровне горизонтальных связей.

Сущность и значение рынка в координатах маркетинговой деятельности физкультурноспортивной организации (ФСО) раскрывается через его функции. Кроме удовлетворения потребностей получателей услуг, к ним следует отнести информационную, ценообразующую, контролирующую и санизирующую функцию (с помощью конкуренции рынок очищает производство товаров и услуг от его экономически неэффективных форм), а также посредническую, призванную стимулировать развитие производства физкультурно-спортивных услуг [4]. По сути, речь идет о гибкости системы в условиях меняющейся внешней среды, адаптивности предложения услуг к изменяющимся потребностям покупателей, формирующих «обратную связь».

Торговля при этом, отражая интересы потребителя и используя «обратную связь», заставляет производство в сфере ФКиС изменяться, адаптируясь к изменившемуся спросу. Маркетинговые исследования при этом обязательно затрагивают вопросы формирования и развития институциональных механизмов взаимодействия отраслевого рынка и спортивного менеджмента. 
Результаты исследования. Обоснование комплексного подхода к маркетинговым исследованиям в сфере физкультурно-спортивной деятельности позволило сформулировать рекомендации о структурном представлении организационно-нормативного (институционального) механизма взаимодействия отраслевого рынка и спортивного менеджмента. Наши исследования касаются также вопросов инфраструктуры рынка, которая затрагивает услуги финансовых учреждений, рекламных и информационных агентств, предприятий торговли. Говоря иначе, речь идет о выполнении рынком ряда вспомогательных функций, в числе которых - функция контроля качества услуг, продаваемых на соответствующих рынках [5].

Последние - с позиций тех же исследований - определенным образом классифицируются. Признаки классификации могут быть самыми различными (территориальный охват, тип конкуренции, уровень сбалансированности, каналы реализации, степень развития, состояние насыщенности).

Особую роль при этом имеют законы функционирования рынка физкультурно-спортивных услуг, в частности, взаимодействие спроса и предложения как основа ценообразования и дифференциация потребностей, который выражается в изменении (со временем) количества видов и структуры потребительских услуг ФСО.

Общепризнанным является положение, согласно которому рынок в координатах маркетинга представляет собой инструментарий для организации и оптимизации физкультурноспортивной деятельности, помогающей ответить на главные вопросы: что, как и сколько производить, а также как продавать и распределять производимые услуги. Под конечной целью маркетинговой деятельности при этом понимается удовлетворение человеческих нужд и потребностей [1]. Подчеркивая это, Г.В.Астратова речь ведет о «ключевых элементах, определяющих рынок в системе маркетинга» [2]. В преломлении к ФСО, это:

- характеристика покупателей, потребности которых необходимо удовлетворять;

- характеристика потребностей, нуждающихся в удовлетворении;

- производственный потенциал ФСО в данный момент времени;

- конкурентная среда предложения услуг.

На основе программы маркетинга, формируемой любой физкультурно-спортивной организацией, ведется поиск рынков, новых потребителей, расширяется область применения производимых услуг [2]. По мнению тех же авторов, следует различать «рынки маркетинговой деятельности», которые в сфере физкультурноспортивной деятельности имеют свои особенности с позиций локальности, однородности, стандартизированности и дифференцированности.

В рамках физкультурно-спортивной деятельности речь можно вести о «концепции мультатрибутивной услуги». Согласно ей, отношение потребителя к рыночной услуге основано на суммированном наборе мнений (предложений) об атрибутах, ее свойствах и сопоставлении их с оценкой данных атрибутов [3].

Отмеченное позволяет сделать вывод о том, что маркетинговая деятельность ФСО имеет дело с целостной системой личных потребностей, содержание и формы которых необходимо

Таблица 1. Комплексный подход к маркетинговым исследованиям в сфере физкультурно-спортивной деятельности

\begin{tabular}{|l|l|}
\hline \multicolumn{1}{|c|}{\begin{tabular}{c}
\multicolumn{1}{|c|}{ Параметр } \\
компексности
\end{tabular}} & \multicolumn{1}{|c|}{ Содержательный аспект маркетинговых исследований рынка } \\
\hline 1. Понятие комплексности & $\begin{array}{l}\text { Это целенаправленный сбор, обработка и анализ информации с целью } \\
\text { уменьшения неопределенности при принятии управленческих решений }\end{array}$ \\
\hline $\begin{array}{l}\text { 2. Функции } \\
\text { ниях и процессах и дает характеристику по объему, структуре, вариации и } \\
\text { динамике); } \\
\text { - аналитическая (исследователь отвечает на вопрос: почему явление до- } \\
\text { стигло такого уровня, развивалось именно такими темпами и какие факторы } \\
\text { повлияли на это); } \\
\text { - прогнозная (основывается на данных, названных выше, функциях и пред- } \\
\text { назначена для прогноза дальнейшего развития событий) }\end{array}$ \\
\hline 3. Цель & $\begin{array}{l}\text { Состоит в информационно-аналитическом обеспечении маркетинговой } \\
\text { деятельности с позиций изучения конъюнктуры рынка и исследования по- } \\
\text { тенциала рынка }\end{array}$ \\
\hline
\end{tabular}




\begin{tabular}{|l|l|}
\hline 4. Уровень исследования & $\begin{array}{l}\text { Макроуровень (дается анализ состояния рынка, закономерностей и тенден- } \\
\text { ций его развития, проводится анализ спроса). } \\
\text { Микроуровень (осуществляется анализ и прогноз собственных возможно- } \\
\text { стей ФСО, оценка ее конкурентоспособности, состояния и перспектив разви- } \\
\text { тия того сегмента рынка, на котором функцонирует данная организация) }\end{array}$ \\
\hline $\begin{array}{l}\text { 5. Оценка емкости } \\
\text { отраслевого рынка }\end{array}$ & $\begin{array}{l}\text { Проводится на основании спроса и предложения, объема ввоза и вывоза } \\
\text { товаров, а также их производства по всем категориям товаропроизводителей }\end{array}$ \\
\hline $\begin{array}{l}\text { 6. Методики оценки } \\
\text { конкурентоспособности } \\
\text { физкульурно-спортивных } \\
\text { услуг }\end{array}$ & $\begin{array}{l}\text { Экспертная оценка } \\
\text { Построение многоугльника конкурентоспособности товара } \\
\text { Матрица Нильсена (оценка коммерческого успеха) }\end{array}$ \\
\hline $\begin{array}{l}\text { 7. Этапы исследования } \\
\text { 8. Направление исследований }\end{array}$ & $\begin{array}{l}\text { Разработка концепции исследования } \\
\text { Получение и анализ эмпирических данных } \\
\text { Формирование основных выводов и результатов исследований }\end{array}$ \\
$\begin{array}{l}\text { Относительно отраслевого рынка и его связи с маркетинговой деятельно- } \\
\text { стью ФсО } \\
\text { С точки зрения конкурентов и потребителей }\end{array}$ \\
\hline
\end{tabular}

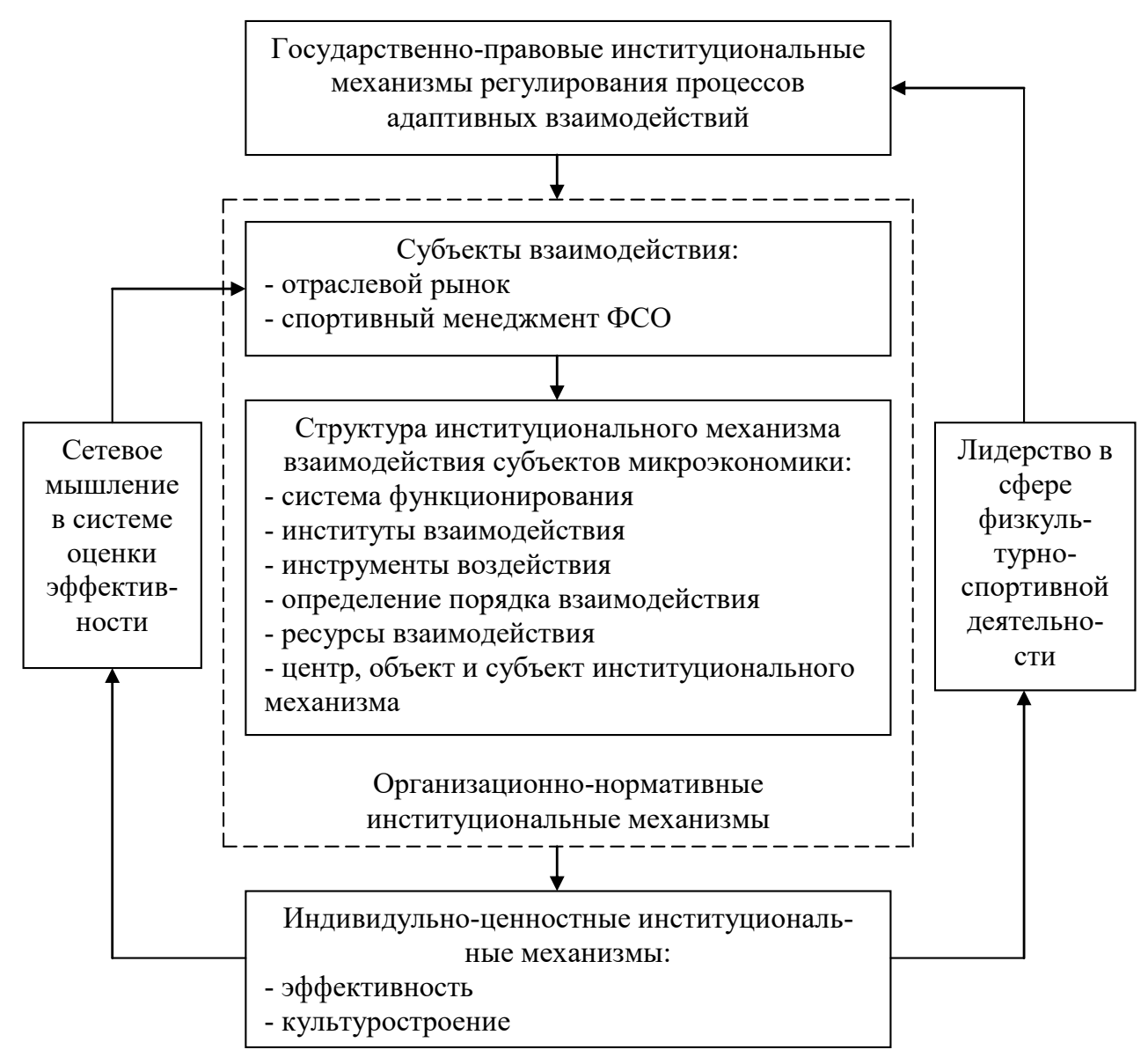

Рисунок 1. Формы институциональных механизмов взаимодействия отраслевого рынка и спортивного менеджмента 
выявить, чтобы понять как действует современный рынок физкультурно-спортивных услуг, к числу которых мы относим и «эмоции». В самом общем виде потребности эти следующие: физиологические, социальные, психологические, интеллектуальные, духовные. Последние потребности особенно важны с позиций самосовершенствования спортивных менеджеров (особенно с позиций высшего «Я»).

В таблице 1 сконцентрирована информация в отношении комплексного подхода к маркетинговым исследованиям рынка физкультурноспортивных услуг. В ней выделено восемь параметров, определяющих данную комплексность, которая имеет важное значение с позиций обеспечения конкурентоспособности на микро- и макроуровне (с учетом особенностей физкультурно-спортивной деятельности).

Конкурентоспособность при этом следует рассматривать на четырех уровнях, каждому из которых соответствуют свои подходы к организации управления маркетингом ФСО.

1. Внутренний нейтральный уровень управления, в основе которого лежит поиск места на рынке (свободного от конкуренции).

2. Внешне нейтральный (стремление стать маркетинго-ориентированной ФСО, в которой все процессы планирования и развития производства услуг базируются на прогнозах, составляемых службой маркетинга).

3. Маркетингоориентированный (в центре внимания находятся нужды и запросы потребителей физкультурно-спортивных услуг).

4. Отраслевое лидерство (в центре внимания находится организационное культуростроение, предназначение которого - дальнейший рост конкурентоспособности физкультурноспортивных услуг).

На рисунке 1 представлены основные формы институциональных механизмов взаимодействия отраслевого рынка и спортивного менеджмента. Прежде всего, это государственно-правовые механизмы. Это также организационно-нормативные и индивидуально-ценностные механизмы.

Нами рассмотрен эндогенный подход к исследованию институционального - государственно-правового - механизма (его алгоритм, систематизация описания, включая цель, алгоритм, условия, ограничения, характеристика оптимальности и эффективности). Данный механизм - это способ ограничения государствен- ного вмешательства в физкультурно-спортивную деятельность рамками точной настройки взаимодействия рассматриваемых субъектов. Конкретно речь идет о следующих аспектах такой настройки:

- экономическая диагностика процессов взаимодействия;

- анализ конкурентной среды (оценка совокупности рыночных сил и факторов, определяющих функционирование исследуемых субъектов);

- изучение рыночной инфраструктуры;

- выявление взаимосвязей, форм и методов регулирования, сущность которого состоит в том, чтобы при использовании разнообразных инструментов создавать механизмы ориентации субъектов рынка на эффективное развитие ФСО без прямого вмешательства органов управления, но в установленных этими органами рамках (формы и методы регулирования при этом должны быть основаны на использовании стимулов, предусматривающих экономическую заинтересованность и ответственность хозяйствующих субъектов).

Структура организационно-нормативного институционального - механизма взаимодействия отраслевого рынка и спортивного менеджмента представлена на рисунке 2 . В качестве определенного комментария отметим, что категория «институциональный механизм» в связи с неуклонным развитием физкультурноспортивной деятельности имеет тенденцию к приобретению новых свойств. Отмеченное, прежде всего, касается организационнонормативного и индивидуально-ценностного механизма. Отсутствуют также научно обоснованные критерии эффективности данных механизмов взаимодействия отраслевого рынка и спортивного менеджмента (при наличии ряда довольно известных его субмоделей).

Важно подчеркнуть, что любой механизм (из приведенных выше): обеспечивает создание правил (с учетом отслеживания последствий их применения); координирует действия (что проявляется через функциональность и согласованность отдельных элементов с целью обеспечения коллективного - на разных уровнях регулирования - делового успеха); контрактные отношения (возникающие между определенными объектами и субъектами рыночной экономики, сгруппированными в иерархическую координационную структуру для достижения опреде- 
ленных целей). Это также система упорядочения взаимосвязей хозяйствующих субъектов и агентов в соответствии с требованиями традиционно существующих и легитимно установленных обществом институтов, действующих в пространственно-временном, структурнофункциональном и историко-логическом аспектах физкультурно-спортивной деятельности в рамках отраслевого рынка. Конкретно речь идет о преобладающих функциях регулирования, методах и инструментах названных ранее институциональных механизмов.

В заключении отметим, что рынок является:

1) объективной социальной основой маркетинга, поскольку проявляется в ходе человеческой деятельности (взаимодействие производителя услуг, продавца и потребителя) и направлен на человека (удовлетворение потребностей конечного потребителя);
2) с позиций маркетинга главной характеристикой состояния потребительского (отраслевого) рынка является удовлетворение спроса по количеству, структурному соотношению, ассортименту и качеству предлагаемых рынком услуг. Это также этичность маркетингового поведения, глобальное мышление руководителей физкультурно-спортивных организаций и планирование данного вида деятельности ФСО в условиях растущего значения качества, цены и удовлетворения потребностей потребителя физкультурно-спортивных услуг;

3) в основе проведенного исследования лежит обоснование механизмов взаимодействия отраслевого рынка и спортивного менеджмента. В качестве рекомендаций дано структурное представление организационно-нормативного (институционального) механизма данного взаимодействия.

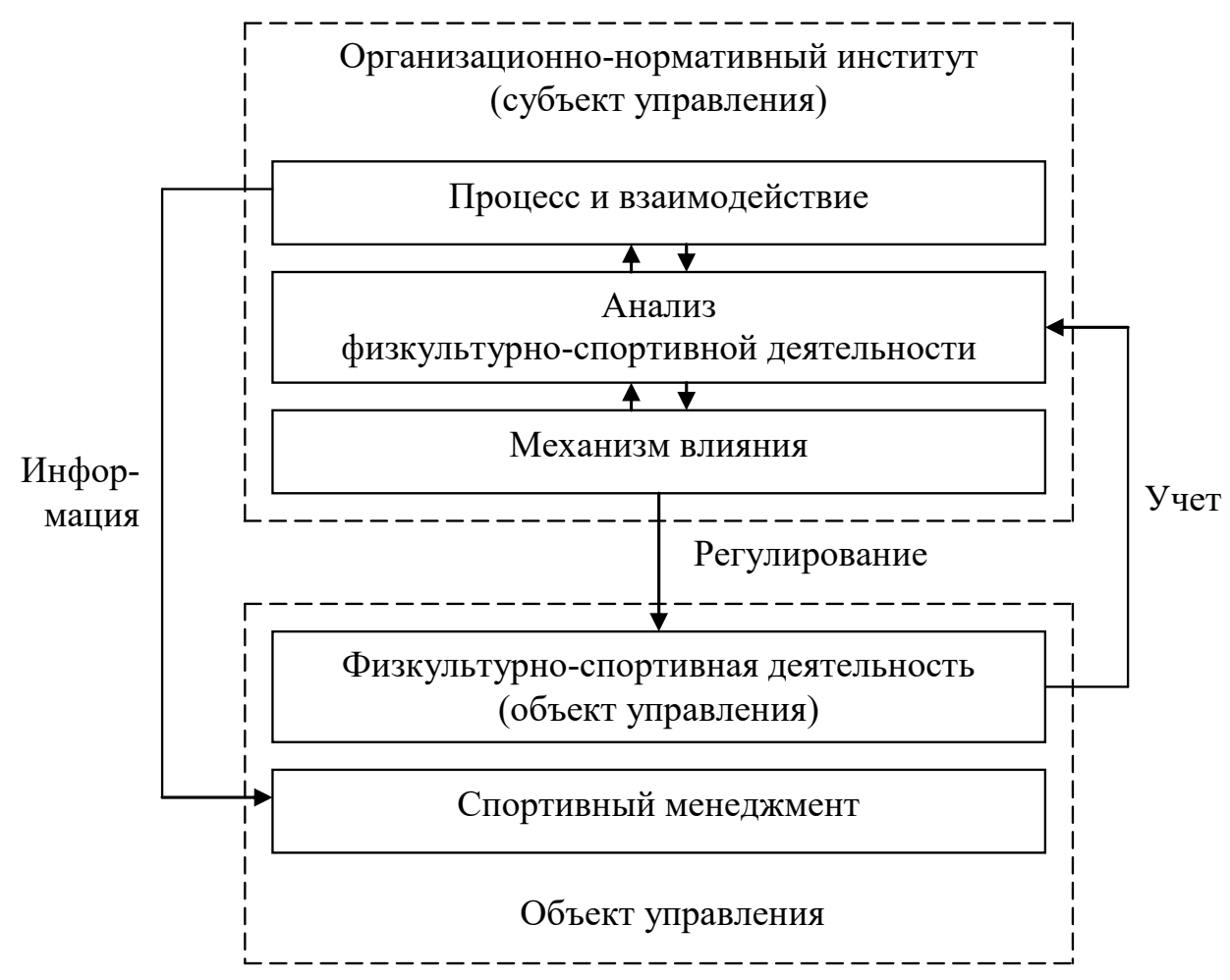

Рисунок 2. Структура организационно-нормативного (институционального) механизма взаимодействия отраслевого рынка и спортивного менеджмента 


\section{Библиографический список}

1. Астратова, Г.В. Маркетинг продовольственного рынка: концептуальный подход / Г. В. Астратова.- Шадринск: ПО «Исеть», 1996.

2. Комлев, С. Посреднические фирмы и оптовая торговля в США / С. Комлев // Материально-техническое снабжение. - 1989. - № 5.- С. 70-73.

3. Ламбен, Ж.-Ж. Стратегический маркетинг. Европейская перспектива / Ж.-Ж. Ламбен.-СПб.: Наука, 1996.

4. Попова, E.A. Моделирование финансовой реструктуризации и оздоровления организации сферы услуг / Е.А. Попова // Эффективные инструменты познания культуры управленческой деятельности.- Магнитогорск: МГТУ, 2016.- С. 84-89.

5. Федоров, М.В. Рынок продовольственного сырья и пищевых продуктов / М.В.Федоров и др.- Екатеринбург: УрГЭУ, 2011.- 300 с. 